\title{
Acetylcholine and Olfactory Perceptual Learning
}

\author{
Donald A. Wilson, ${ }^{1}$ Max L. Fletcher, and Regina M. Sullivan \\ Department of Zoology, University of Oklahoma, Norman, Oklahoma 73019, USA
}

\begin{abstract}
Olfactory perceptual learning is a relatively long-term, learned increase in perceptual acuity, and has been described in both humans and animals. Data from recent electrophysiological studies have indicated that olfactory perceptual learning may be correlated with changes in odorant receptive fields of neurons in the olfactory bulb and piriform cortex. These changes include enhanced representation of the molecular features of familiar odors by mitral cells in the olfactory bulb, and synthetic coding of multiple coincident odorant features into odor objects by cortical neurons. In this paper, data are reviewed that show the critical role of acetylcholine (Ach) in olfactory system function and plasticity, and cholinergic modulation of olfactory perceptual learning at both the behavioral and cortical level.
\end{abstract}

Olfactory memory plays an important role in many aspects of mammalian behavior including mate choice and recognition (Brennan and Keverne 1997), mother-infant interactions (Kendrick et al. 1992; Leon 1992; Wilson and Sullivan 1994; Fleming et al. 1999; Sullivan et al. 2000a), food localization and preferences (Mennella and Beauchamp 2002), and emotional state (Otto et al. 2000). For the most part, the study of olfactory memory has focused on associative memory in which the odor signaling a mate, offspring, mother, or appetitive or aversive stimulus has been learned through temporal association between the odor and the stimulus. Through the learned association, the odor can come to elicit situation specific and appropriate behavioral responses. Acetylcholine (Ach) is an important modulator of olfactory associative memory, with both pharmacological receptor blockade (Ravel et al. 1994; DeRosa and Hasselmo 2000) and lesions of cholinergic projections neurons (Roman et al. 1993; Linster et al. 2001) able to impair acquisition. Similarly, impairments in olfactory memory associated with Alzheimer's disease, may be at least partly mediated by cholinergic dysfunction (Coyle et al. 1983).

Another form of olfactory learning, and the focus of this review, is perceptual learning. Perceptual learning results in a form of implicit memory that allows for enhanced perceptual discrimination (perceptual acuity) of previously experienced stimuli. Recent evidence indicates that behavioral olfactory perceptual learning and its neural correlates are modulated by acetylcholine.

\section{Olfactory Perceptual Learning}

Perceptual learning has several defining characteristics (Gilbert et al. 2001). First, the learned changes in perceptual acuity are largely specific for the trained stimuli, with some minimal generalization or transfer, and are long-lasting. Second, the learned changes generally do not occur following passive stimulation, but require attention by the animal. The attentional component can be mimicked by activation of cholinergic systems (Rasmusson and Dykes 1988; Metherate and Weinberger 1989; Edeline et al. 1994). Finally, the learned changes in behavioral acuity are often correlated with changes in cortical receptive fields. Examples of perceptual learning include improvements in somatosensory discrimination of spatially or temporally varied tactile stimuli (Recanzone et al. 1992a; Godde et al. 1996), improvements in auditory discrimination of small variations in pitch of

\section{'Corresponding author.}

E-MAIL dwilson@ou.edu; FAX (405) 325-2699.

Article and publication are at http://www.learnmem.org/cgi/doi/10.1101/ Im.66404. sound stimuli (Delhommeau et al. 2002; Demany and Semal 2002), and improvement in discrimination of minor offsets in vertically or horizontally oriented discontinuous lines in a visual vernier acuity task (McKee and Westheimer 1978; Fahle and Edelman 1993).

Perceptual learning can also include changes in figureground perceptual grouping and identification of collections of visual features as single, unique visual objects, such as faces (Rolls 2000). For example, in the classic perceptual grouping stimulus consisting of a high-contrast image of a Dalmatian dog drinking from a water dish, determining which spots constitute the Dalmatian (which visual features should be grouped into the single visual object of Dalmatian) and which constitute the background is greatly facilitated by previous experience with the image and with Dalmatian dogs.

In the olfactory system, perceptual learning has been hypothesized to be critical for normal olfactory discrimination (Cleland et al. 2002; Fletcher and Wilson 2002; Wilson and Stevenson 2003). Most odors experienced in the environment are complex mixtures, and even monomolecular odorants are hypothesized to be processed by the olfactory periphery as composed of multiple features (Polak 1973). However, despite the complex nature of odor stimuli, odors are generally perceived to be unique single stimuli, or odor objects (Liang and Francis 1989; Wilson and Stevenson 2003), which may or may not share similarities with their components (e.g., Linster and Smith 1999; Kay et al. 2003). In fact, the ability to analytically process odors (identify components within mixtures) is severely limited when mixtures exceed three or four components (Liang and Francis 1989). Thus, olfactory perception appears to be highly synthetic (configural), whereas initial, peripheral odorant processing is highly analytical (Mori et al. 1999). It has been proposed that the synthetic nature of olfactory perception, that is, treating complex odorant stimuli as single odor objects, involves and in fact requires learning (Granger and Lynch 1991; Hudson 1999; Haberly 2001; Wilson and Stevenson 2003). Through experience, combinations of odorant features extracted at the periphery become synthesized into odor objects by central cortical circuits (Wilson 2003).

In addition to the synthesis of odor objects, and potentially as a by-product of this synthesis, perceptual learning can also enhance discriminability of similar odorants. For example, in human subjects, exposure to previously unfamiliar odorants significantly enhances discriminability of those odorants from each other compared with performance of subjects that did not receive the initial familiarization regime (Rabin 1988; Jehl et al. 1995). Similarly, rats are very poor at discrimination of novel ethyl ester molecules differing in length by a single carbon, but 
have no difficulty discriminating novel ethyl esters differing by four carbons (Fletcher and Wilson 2002). However, prior associative training with one of the ester odors significantly enhances discriminability of that odor from esters differing by one carbon, $24 \mathrm{~h}$ later. Similar results have been obtained in several olfactory perceptual learning paradigms (Cleland et al. 2002; Linster et al. 2002).

Importantly, just as in perceptual learning in other sensory systems, olfactory perceptual learning shows limited generalization. Thus, training an animal with a seven-carbon ester (ethyl heptanoate) enhances discrimination between that odorant and an eight-carbon ester (ethyl octanoate). Training to ethyl heptanoate also enhances other one-carbon discriminations of ethyl esters, such as between ethyl butyrate and ethyl valerate. However, training to the slightly different molecule isoamyl acetate does not generalize to the ethyl esters (Fletcher and Wilson 2002).

Thus, as an animal learns that a particular odor signals an aversive or appetitive reward, at the same time the representation of that odor is somehow modified to make it more distinctive from other similar odors. Our recent work indicates that this modification in the odor representation occurs in both the olfactory bulb and piriform cortex, but it is the piriform cortical changes that underlie the synthetic nature of olfaction. Importantly, both behavioral olfactory perceptual learning and presumed neural correlates in the piriform cortex are ACh-dependent.

\section{Neural Correlates of Olfactory Perceptual Learning}

It is hypothesized that olfactory perceptual learning, as with perceptual learning in other sensory systems, is associated with changes in receptive fields of central neurons (Gilbert et al. 2001). Second-order neurons in the olfactory system, olfactory bulb mitral cells, and third-order neurons, piriform cortical pyramidal cells, display odorant receptive fields for stimuli in odorant space. An experience-dependent change in these receptive fields, for example, enhancement in contrast between similar odorant features encoded by mitral cells, or enhancement in combinatorial synthesis by piriform cortical neurons, could improve behavioral odor discrimination.

\section{Olfactory Bulb Mitral Cells}

Specific mitral cells receive direct excitatory input from a genotypically homogeneous population of olfactory receptor neurons that synapse on the mitral cell apical dendritic tuft within the glomerular neuropil (Vassar et al. 1994; Tsuboi 1999). Olfactory receptor neurons (Malnic et al. 1999; Araneda et al. 2000; Firestein 2001; Wachowiak and Cohen 2001) and olfactory bulb glomeruli (Friedrich and Korsching 1997; Rubin and Katz 1999; Uchida et al. 2000; Meister and Bonhoeffer 2001; Johnson et al. 2002) have odorant receptive fields for molecular features, rather than odorant molecules as a whole, and thus respond to many odorants as long as that molecular feature is present. Odorant features may include such things as a particular range of carbon chain lengths, the presence or location of a functional group, some combination of these, or some yet-to-be-determined variables (Mori et al. 1999). As might be expected given the direct excitatory receptor input, mitral cell odorant receptive fields are very similar to those of receptor neurons (Mori et al. 1999), responding to multiple odorants sharing a common feature. Crosshabituation studies indicate that habituation to that feature reduces responsiveness of the mitral cell to all odorants within its receptive field, as would be expected for a feature-detecting neuron.

Mitral cell odorant receptive fields and odorant responsiveness can be modified by experience. Work from several labs has shown that associative odor conditioning (Freeman and Schneider 1982; Faber et al. 1999; Ravel et al. 2003) and even simple odorant exposure (Buonviso and Chaput 2000; PerezOrive et al. 2002) can modify subsequent mitral cell responsive- ness and/or olfactory bulb local field potential responses to those odorants. As described below, olfactory bulb changes may also underlie learning involved with biologically significant events such as mother-infant interactions (Coopersmith and Leon 1984; Kendrick et al. 1992; Wilson and Sullivan 1994; Brennan and Keverne 1997).

Although these studies have demonstrated changes in evoked responses to specific odors, they have not examined changes across the odorant receptive field. Recently, we have demonstrated that simple odor exposure can produce shifts in odorant receptive fields toward the exposed odor (Fletcher and Wilson 2003). Odorant receptive fields of mitral cells for a homologous series of ethyl esters were mapped before and up to $1 \mathrm{~h}$ after a 50-sec exposure to one of the odorants within the receptive field. The exposure odorant was either the ester with a carbon chain length that produced the maximal response in the cell, or an ester that had a carbon chain length two carbons longer than the most effective odorant. For cells exposed to the maximally effective stimulus (and in unexposed control cells), there was an initial generalized habituation across the receptive field immediately after the exposure, but following recovery from habituation, the general shape of the odorant receptive field did not change over the course of the hour. However, in cells exposed to an odor two carbons away from the peak, the odorant receptive field demonstrated a significant shift toward the exposure odorant by the end of the 1-h recording. In some cases, this shift was sufficient to make the exposure odor become the new most effective odorant for that cell (Fletcher and Wilson 2003).

These exposure-induced changes in mitral cell odorant receptive fields are highly reminiscent of receptive field plasticity in other sensory systems (Gilbert et al. 2001). In thalamocortical sensory systems, single neurons receive input from diverse afferents with a subset of afferents more effective at driving the cell than others. For example, thalamic and cortical neurons in the auditory pathway receive inputs conveying information about a variety of tonal frequencies, some of which are more effective than others, resulting in a receptive field in frequency space where the cell is maximally responsive to certain frequencies (Weinberger 1995). Experience can shift this receptive field by modifying the relative strength of the afferent synapses coding the experienced frequency, producing an enhanced representation of the learned tone, and presumably, enhanced discriminability of that tone (Weinberger 1995). Changes in lateral inhibition (Pettet and Gilbert 1992; Xing and Gerstein 1994) and temporal synchrony of coactive cells (Recanzone et al. 1992b) can also manifest changes in receptive fields that could contribute to perceptual learning in thalamocortical systems.

In contrast, given the homogeneous receptor input to mitral cells, plasticity of diverse afferents does not at first seem to be a likely mechanism of mitral cell odorant receptive field experience-induced change. However, the glutamatergic olfactory receptor-to-mitral cell synapse can express plasticity of such longterm potentiation (Ennis et al. 1998); thus, past activity could influence subsequent response patterns. A change in afferent synaptic strength could modify the balance between afferent excitation and the extensive lateral inhibitory networks impinging on mitral cells, potentially resulting in a shifted odorant receptive field.

In addition, the inhibitory networks themselves may undergo experience-dependent plasticity that could result in modified receptive fields. For example, dopamine release from juxtaglomerular neurons can act presynaptically on receptor neuron afferents to reduce receptor activation of bulb circuits (Sallaz and Jourdan 1992; Wachowiak and Cohen 1999; Ennis et al. 2001) and mitral cell odor responsiveness (Wilson and Sullivan 1995). Juxtaglomerular cell dopamine expression is regulated by affer- 
ent activity, with decreased afferent input producing dramatic, rapid down-regulation of dopamine synthesis (Baker et al. 1988; Philpot et al. 1998). Thus, prolonged exposure to a particular odor or odorant feature could modulate dopamine release (Coopersmith et al. 1991) and subsequent mitral cell odorant receptive fields.

Inhibitory granule cells, which form the largest population of olfactory bulb neurons, are also a prime candidate for experience-dependent change. Granule cells form dendrodendritic reciprocal synapses with mitral cells and are also the primary target of centrifugal fibers to the bulb. Associative odor learning activates c-fos expression in granule cells (Woo et al. 1996; Allingham et al. 1999), neurogenesis/survival of newly formed granule cells (Rochefort et al. 2002), odor-evoked GABA release (Brennan et al. 1998; Okutani et al. 1999), and, in some cases, mitral cell suppressive responses to learned odors (Wilson et al. 1987).

Together, these mechanisms could result in modified mitral cell odorant receptive fields and refinement in odorant feature encoding, and, in turn, contribute to experience-dependent changes in odorant discrimination as described above. Perhaps most importantly, the refined olfactory bulb output could contribute to greater fidelity in the synthetic coding of odorant objects in the piriform cortex, as described below.

\section{Piriform Cortex}

As noted above, odorant receptive fields of neurons in the piriform cortex differ from those of mitral cells in that cortical neurons appear to respond to odorants as a whole, rather than to individual odorant features. The best evidence of this synthetic nature of cortical odorant receptive fields comes from cross-habituation studies. As noted above, in mitral cells, habituation to one odor produces cross-habituation to the other odors within the receptive field. However, in piriform cortical neurons, habituation to one odorant produces only slight cross-habituation to the other odorants within the receptive field (Wilson 1998a). In fact, habituation to a binary mixture produces minimal crosshabituation to the components (Wilson 2003), indicating that the cortical neuron treats the mixture as a unique odorant object, different from the components.

Importantly, however, the enhanced odorant discrimination in the piriform cortex requires experience (Fig. 1A). When exposed to novel odorants for $<10-20 \mathrm{sec}$, piriform cortical neurons behave like feature-detecting mitral cells and show strong cross-habituation. Only when exposed to odorants for at least 50 sec do the enhanced discrimination and synthetic processing phenomena become apparent (Wilson 2003). These results indicate that cortical neurons/circuits "learn" to synthesize the combination of features present in an odorant into an odorant object, but that this learning takes time.

Synthesis of features within the piriform cortex could occur through convergence of mitral cell axons conveying activity from different olfactory receptors (Zou et al. 2001), and/or convergence of the broadly dispersed intracortical association fiber system (Haberly 2001). We propose that most plasticity-dependent synthesis occurs via the intracortical association fiber system for at least two reasons. First, the mitral cell synapses show robust activity-dependent short-term depression during prolonged odor stimulation (Wilson 1998b) or tetanic stimulation (Best and Wilson 2002). This depression may contribute to cortical odor habituation (Wilson 1998b), but presumably does not enhance synthetic coding. The second reason to focus on the association fiber system is that these synapses display robust, activity-dependent associative long-term potentiation (Stripling et al. 1988; Kanter and Haberly 1990; Patil et al. 1998), precisely the type of mechanism that could allow for experience-induced synthetic coding of coactive inputs. Computational models of the piriform cortex (Granger and Lynch 1991; Hasselmo et al. 1992; Hasselmo and Barkai 1995) support a role of association fiber plasticity in olfactory associative memory function.

Thus, experience-dependent associative plasticity of cortical synapses is proposed as a mechanism of synthetic coding in the piriform cortex. Once the combinations of odorant features expressed in an odor are encoded synthetically in the cortex, cortical neurons can continue to respond even in situations of partially degraded input, thus treating stimuli composed of multiple features as single objects and enhancing discriminability between those objects. We hypothesize that it is this enhancement of cortical discrimination and synthetic coding that drives enhanced odor acuity at the behavioral level.

\section{Acetylcholine and Olfactory Perceptual Learning}

ACh from the basal forebrain has been demonstrated to serve an important function in attention, arousal, learning and memory, as well as the hypothesized neural substrates of these behavioral phenomena in a wide variety of experimental paradigms (e.g., Deutsch 1971; Bear and Singer 1986; Givens and Olton 1994; Aigner 1995; Bakin and Weinberger 1996; Blokland 1996; Sarter and Bruno 1997; Kilgard and Merzenich 1998). For example, in the auditory system, both learned behavioral tone discrimination and the suspected neural correlates of auditory conditioning are similarly modulated by manipulations of cholinergic systems-disruption of normal cholinergic activity impairs behavioral auditory conditioning and neural plasticity, whereas enhancement of cholinergic activity facilitates behavioral learning and cortical plasticity (e.g., Caine et al. 1981; Bakin and Weinberger 1996; Kilgard and Merzenich 1998; McLin III et al. 2002).

In olfaction, both behavioral perceptual learning and its hypothesized neural correlates are modulated by ACh (Fig. 1B,C). The cholinergic projections to the olfactory bulb and piriform cortex arise primarily from the horizontal limb of the diagonal band of Broca (HLDB; Shute and Lewis 1967; Wenk et al. 1977; Macrides et al. 1981; Luskin and Price 1982; Zaborszky et al. 1986). Interestingly, this area also receives input from the olfactory system (Broadwell 1975; Linster and Hasselmo 2000); thus, cholinergic feedback can be, at least in part, regulated by odorant stimulation itself. ACh modulates several aspects of central olfactory neuron physiology and circuit function that may be important for perceptual learning. Furthermore, disruption of olfactory system ACh increases behavioral generalization between molecularly similar odors (Linster et al. 2001) and impairs olfactory perceptual learning (Fletcher and Wilson 2002), whereas the ACh agonist physostigmine can enhance odor discrimination in rats (Doty et al. 1999).

Although there may be a small population of intrinsic cholinergic neurons in both the olfactory bulb and piriform cortex (Phelps et al. 1992), the majority of cholinergic input to these olfactory structures originates in the basal forebrain nucleus of the HLDB. In the olfactory bulb, cholinergic fibers terminate in all layers, although they are significantly densest in the internal plexiform layer and glomerular layer (Carson and Burd 1980; Halasz and Shepherd 1983; Kasa et al. 1995). ACh has several disparate postsynaptic consequences in the olfactory bulb, mediated by both muscarinic and nicotinic receptors (Nickell and Shipley 1988b; Ravel et al. 1990; Elaagouby et al. 1991; Castillo et al. 1999), although the primary target appears to be interneurons (Nickell and Shipley 1988a; Kunze et al. 1991; Kasa et al. 1995). ACh infusion into the olfactory bulb can produce not only immediate modulation of bulb circuit excitability (Elaagouby et al. 1991) but also more long-lasting increases in bulb excitability (Elaagouby and Gervais 1992). Blockade of olfactory bulb muscarinic receptors with scopolamine disrupts short-term memory in an olfactory delayed match-to-sample task (Ravel et al. 1994).

\section{Learning \& Memory}

www.learnmem.org 
In the piriform cortex, cholinergic fibers from the HLDB terminate heavily in Layers II and III and less heavily in Layer I, and in contrast to the olfactory, the primary target appears to be the principal output neurons, pyramidal cells of Layers II and III (Luskin and Price 1982). ACh appears to have three major functional consequences on piriform cortical circuit function: (1) a selective modulation of intracortical association fiber synapses, with minimal effects on afferent synapses (Hasselmo and Bower 1992; Linster et al. 1999); (2) a reduction in pyramidal cell afterhyperpolarization and spiking adaptation to current steps, and thus a potential increase in signal-to-noise ratios (Barkai and Hasselmo 1994; Saar et al. 2001); and (3) modulation of long-term potentiation of association fiber synapses (Hasselmo and Barkai 1995). Acetylcholine does not appear to modulate cortical habituation to odorants (Chabaud et al 2000; Wilson 2001).

As noted above, blockade of ACh in the olfactory system or

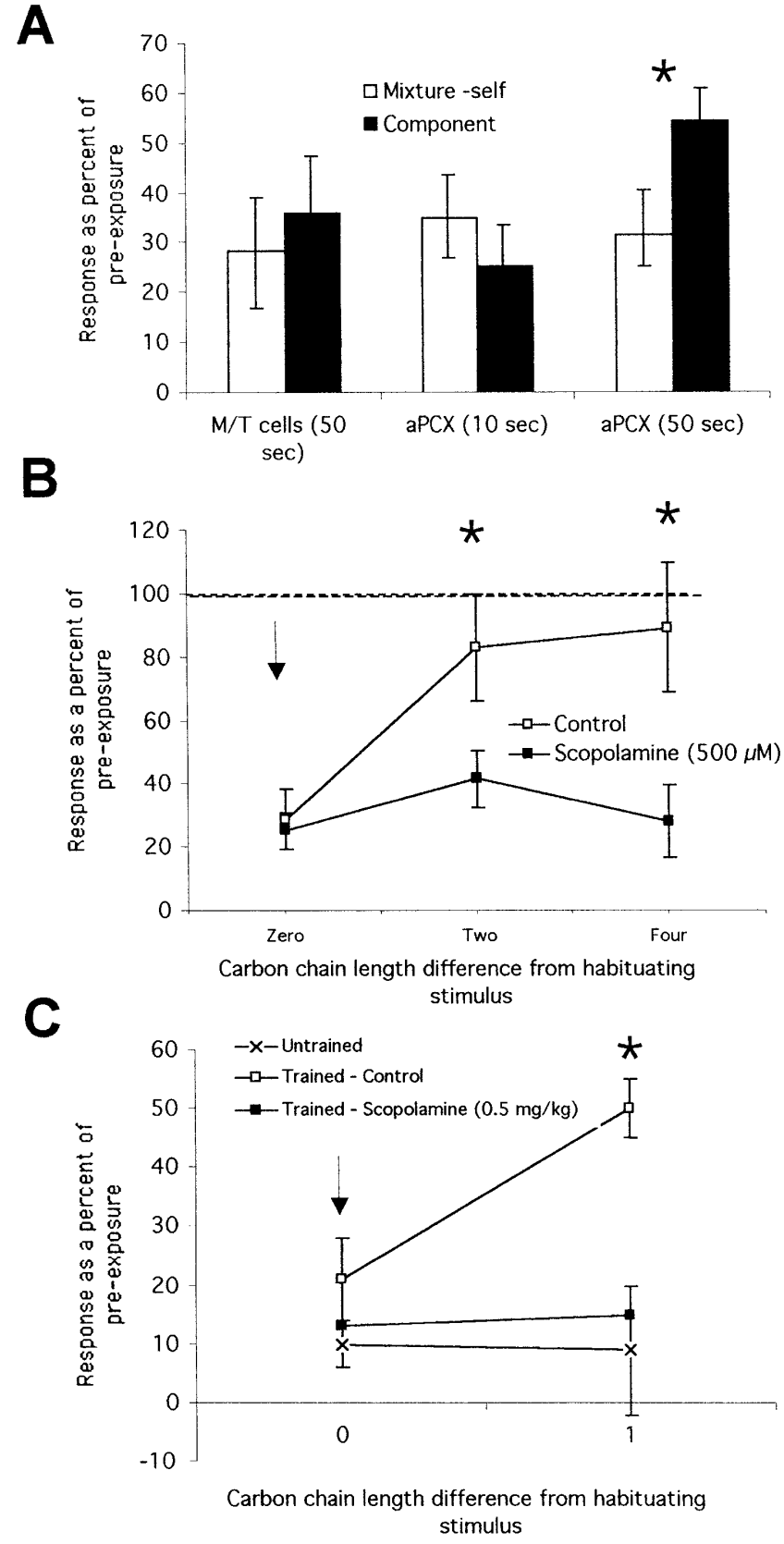

lesions of the HLDB impair olfactory memory in several paradigms (Ravel et al. 1994; DeRosa and Hasselmo 2000; Linster et al. 2001; Saar et al. 2001). Similarly, systemic scopolamine injections impair olfactory perceptual learning (Fletcher and Wilson 2002). Fletcher and Wilson (2002) trained animals with a novel odorant (15 4-sec odor stimuli paired with footshock) after receiving either an injection of scopolamine $(0.2$ or $0.5 \mathrm{mg} / \mathrm{kg})$ or saline and then returned the rats to their home cages. The next day, odorant discrimination tests were performed between the trained odorant and odorants in a homologous series varying in carbon chain length. Animals that had been trained the previous day with saline injections were able to discriminate the trained odorant from an odorant differing by a single carbon (e.g., ethyl heptanoate vs. ethyl octanoate). Completely untrained animals cannot make this discrimination, indicating that the trained animals are showing perceptual learning. However, blockade of cholinergic muscarinic receptors with $0.5 \mathrm{mg} / \mathrm{kg}$ scopolamine during training (there was no drug present during testing) prevented this perceptual learning. Scopolamine-injected animals were unable to make the one-carbon difference discrimination, performing similarly to untrained controls.

These results imply that ACh is an important modulator of olfactory perceptual learning. Given the neural circuitry and synaptic functions described above, ACh could impose this modulation via actions within the olfactory bulb, piriform cortex, or both. Results from computational modeling indicate that cholinergic modulation of lateral inhibition in the olfactory bulb could enhance distinctiveness of activity patterns evoked by similar odorants and thus enhance behavioral discrimination of those odorants (Linster and Cleland 2002). Thus, if initial exposure and attention to odorants enhanced cholinergic release in the olfactory bulb, there could be a resulting increase in lateral inhibition and increase in odor discrimination. However, to account for the long duration of olfactory perceptual learning described above, these cholinergic-induced changes in lateral inhibition would similarly have to extend beyond the initial training phase. Now that exposure-induced changes in mitral cell odorant receptive fields have been described (Fletcher and Wilson 2003), investigation of the role of ACh in this plasticity is warranted.

Computational modeling and experimental analysis of cholinergic effects in the piriform cortex, on the other hand, imply that training or attention-induced ACh cortical release could produce long-lasting changes in the strength of association fiber synapses, which could hypothetically result in storage of synthetic representations of the experienced or learned odor (Has-

Figure 1 Odor discrimination is enhanced by experience and modulated by acetylcholine. (A) Following $50 \mathrm{sec}$ of exposure to a novel binary mixture, olfactory bulb mitral cells show poor discrimination of the mixture from its components (strong cross-habituation), while cells in the anterior piriform cortex could show discrimination (only weak cross habituation). The enhanced cortical discrimination, however, requires sufficient past experience. Exposure to a novel mixture for only $10 \mathrm{sec}$ is insufficient to allow good discrimination between the mixture and its components. These data are consistent with experience-dependent synthetic coding in the piriform cortex, with familiar mixtures treated as unique odor objects, distinct from their components (from Wilson 2003). (B) The experience-induced enhancement in cortical odor discrimination can be blocked by application of the muscarinic receptor antagonist scopolamine to the piriform cortical surface during exposure to the novel odorant. Similar results are observed after systemic $0.5 \mathrm{mg} / \mathrm{kg}$ scopolamine injections. In this example, cells are tested for discrimination of alkanes differing in carbon chain length (from Wilson 2001). (C) Prior exposure enhances discriminability of similar odorants (ethyl esters varying in carbon chain length) behaviorally, as assessed with odor-evoked cardiac orienting responses (cf. trained vs. untrained cross-habituation). Systemic scopolamine during the training phase prevents this perceptual learning (from Fletcher and Wilson 2002). 
selmo and Barkai 1995; Saar et al. 1999). In fact, scopolamine either given systemically at the same dose that blocks behavioral olfactory perceptual learning or applied directly to the surface of the piriform cortex prevents exposure-induced enhancement of odor discrimination by cortical neurons (Wilson 2001).

Specifically, as described above, pyramidal-cell single units in the piriform cortex show enhanced discrimination of similar odorants after $50 \mathrm{sec}$ of exposure to those odorants compared with cortical discrimination of completely novel odorants $(<10$ sec of exposure), and compared with olfactory bulb mitral cell discrimination. This emergence of enhanced cortical discrimination over the course of the 50-sec odorant exposure indicates that the cortex may be learning that a particular combination of coincident odorant features represents a single odor object. Disruption of cortical cholinergic input during the odorant exposure, which impairs normal cortical plasticity, prevents the emergence of enhanced odor discrimination by cortical neurons (Wilson 2001).

Thus, these results describe a modulatory role of ACh in olfactory perceptual learning at both the behavioral and cortical single-unit level. The results imply that attention or arousal, which can elevate cholinergic release by basal forebrain neurons (Acquas et al. 1996), could not only enhance the probability of associative, declarative memory for the odor (e.g., this odor signals reward), but also enhance the perceptual distinctiveness of that stimulus from similar stimuli.

\section{Early Olfactory Learning: A Special Case?}

The rat olfactory system is functional early in development, and learned odors are critical for neonatal survival in many mammalian species. In rats, neonates learn the odor of their mother through an associative conditioning mechanism involving pairing of maternal odor with other maternal stimuli such as warmth, milk, and grooming (Hofer and Sullivan 2001). The pups learn both an approach response and generalized behavioral activation to the maternal odor. Given the effects of early experience in other sensory systems, it seems likely that this early learning may not only result in learned preferences, but also affect perceptual olfactory acuity. To our knowledge, however, olfactory perceptual learning in neonates has not been examined.

Early associative olfactory learning is correlated with specific changes in olfactory bulb processing of the learned odors (Coopersmith and Leon 1984; Wilson and Sullivan 1994), and these changes require activation of centrifugal inputs to the bulb during conditioning. The most thoroughly studied of these inputs is norepinephrine (NE) from the locus coeruleus (Sullivan et al. 1989; Sullivan and Wilson 1994). Blockade of NE- $\beta$ receptors within the olfactory bulb (Sullivan et al. 1992) or lesions of the locus coeruleus (Sullivan et al. 1994) during training prevent early olfactory learning, whereas activation of NE- $\beta$ receptors within the olfactory bulb (Sullivan et al. 2000b) or pharmacological stimulation of the locus coeruleus (Sullivan et al. 2000b), paired with odor stimulation, allows early olfactory learning.

Of particular relevance to the present review, cholinergic stimulation of the locus coeruleus, which enhances mitral cell responsiveness to olfactory nerve input (Jiang et al. 1996), is sufficient to produce a learned odor preference in neonates when paired with odor stimulation (Sullivan et al. 2000b). ACh can also directly modulate NE release from locus coeruleus terminals within the olfactory bulb (El-Etri et al. 1999), thus serving as another site for interaction between these systems in regulation of early olfactory learning. It is yet to be determined if this learned preference is associated with a change in perceptual acuity for the learned odor, but these results imply an important role of ACh in olfactory learning throughout life.

\section{Summary}

Olfactory perceptual learning is a rapid form of plasticity with neural correlates in both the olfactory bulb and piriform cortex. Olfactory perceptual learning may be critical for normal synthetic coding of complex odorants to allow recognition of perceptual odor objects. ACh plays a critical role in modulating behavioral perceptual learning and its cortical neural correlates. Thus, disturbance of cholinergic function could have a significant impact on normal olfactory function and implicit olfactory memory.

\section{ACKNOWLEDGMENTS}

This work was supported by grant DC03906 from the NIDCD and a grant from the Oklahoma Center for the Advancement of Science and Technology to D.A.W., predoctoral NRSA fellowship DC006126 from NIDCD to M.L.F., and grants HD33402 from NIDCD and IBN0117234 from NSF to R.M.S.

\section{REFERENCES}

Acquas, E., Wilson, C., and Fibiger, H.C. 1996. Conditioned and unconditioned stimuli increase frontal cortical and hippocampal acetylcholine release: Effects of novelty, habituation, and fear. $J$. Neurosci. 16: 3089-3096.

Aigner, T.G. 1995. Pharmacology of memory: Cholinergic-glutamatergic interactions. Curr. Opin. Neurobiol. 5: 155-160.

Allingham, K., Brennan, P.A., Distel, H., and Hudson, R. 1999. Expression of c-fos in the main olfactory bulb of neonatal rabbits in response to garlic as a novel and conditioned odour. Behav. Brain Res. 104: $157-167$.

Araneda, R.C., Kini, A.D., and Firestein, S. 2000. The molecular receptive range of an odorant receptor. Nat. Neurosci. 3: 1248-1255.

Baker, H., Towle, A.C., and Margolis, F.L. 1988. Differential afferent regulation of dopaminergic and GABAergic neurons in the mouse main olfactory bulb. Brain Res. 450: 69-80.

Bakin, J.S. and Weinberger, N.M. 1996. Induction of a physiological memory in the cerebral cortex by stimulation of the nucleus basalis. Proc. Natl. Acad. Sci. 93: 11219-11224.

Barkai, E. and Hasselmo, M.E. 1994. Modulation of the input/output function of rat piriform cortex pyramidal cells. J. Neurophysiol. 72: 644-658.

Bear, M.F. and Singer, W. 1986. Modulation of visual cortical plasticity by acetylcholine and noradrenaline. Nature 320: 172-176.

Best, A.R. and Wilson, D.A. 2002. Synaptic correlates of cortical adaptation. Society for Neurosciences Abstracts, Orlando, FL.

Blokland, A. 1996. Acetylcholine: A neurotransmitter for learning and memory? Brain Res. Rev. 21: 285-300.

Brennan, P.A. and Keverne, E.B. 1997. Neural mechanisms of mammalian olfactory learning. Prog. Neurobiol. 51: 457-481.

Brennan, P.A., Schellinck, H.M., de la Riva, C., Kendrick, K.M., and Keverne E.B. 1998. Changes in neurotransmitter release in the main olfactory bulb following an olfactory conditioning procedure in mice. Neuroscience 87: 583-590.

Broadwell, R.D. 1975. Olfactory relationships of the telencephalon and diencephalons in the rabbit: I. An autoradiographic study of the efferent connections of the main and accessory olfactory bulb. $J$. Comp. Neurol. 163: 329-345.

Buonviso, N. and Chaput, M. 2000. Olfactory experience decreases responsiveness of the olfactory bulb in the adult rat. Neuroscience 95: $325-332$.

Caine, E.D., Weingartner, H., Ludlow, C.L., Cudahy, E.A., and Wehry, S. 1981. Qualitative analysis of scopolamine-induced amnesia. Psychopharmacology, 74: 74-80.

Carson, K.A. and Burd, G.D. 1980. Localization of acetylcholinesterase in the main and accessory olfactory bulbs of the mouse by light and electron microscopic histochemistry. J. Comp. Neurol. 191: 353-371.

Castillo, P.E., Carleton, A., Vincent, J.D., and Lledo, P.M. 1999. Multiple and opposing roles of cholinergic transmission in the main olfactory bulb. I. Neurosci. 19: 9180-9191.

Chabaud, P., Ravel, N., Wilson, D.A., Mouly, A.M., Vigouroux, M., Farget, V., and Gervais, R. 2000. Exposure to behaviourally relevant odour reveals differential characteristics in rat central olfactory pathways as studied through oscillatory activities. Chem. Senses 25: $561-573$.

Cleland, T.A., Morse, A., Yue, E.L., and Linster, C. 2002. Behavioral models for odor similarity. Behav. Neurosci. 116: 222-231.

Coopersmith, R. and Leon, M. 1984. Enhanced neural response to familiar olfactory cues. Science 225: 849-851.

\section{Learning \& Memory


Coopersmith, R., Weihmuller, F.B., Kirstein, C.L., Marshall, J.F., and Leon, M. 1991. Extracellular dopamine increases in the neonatal olfactory bulb during odor preference training. Brain Res. 564: 149-153.

Coyle, J.T., Price, D.L., and DeLong, M.E. 1983. Alzheimer's disease: A disorder of cortical cholinergic innervation. Science 219: 1184-1188.

Delhommeau, K., Micheyl, C., Jouvent, R., and Collet, L. 2002. Transfer of learning across durations and ears in auditory frequency discrimination. Percept. Psychophys. 64: 426-436.

Demany, L. and Semal, C. 2002. Learning to perceive pitch differences. J. Acoust. Soc. Am. 111: 1377-1388.

DeRosa, E. and Hasselmo, M.E. 2000. Muscarininc cholinergic neuromodulation reduces proactive interference between stored odor memories during associative learning in rats. Behav. Neurosci. 114: $32-41$.

Deutsch, J.A. 1971. The cholinergic synapse and the site of memory. Science 174: 788-794.

Doty, R.L., Bagla, R., and Kim, N. 1999. Physostigmine enhances performance on an odor mixture discrimination test. Physiol. Behav. 65: $801-804$

Edeline, J.M., Hars, B., Maho, C., and Hennevin, E. 1994. Transient and prolonged facilitation of tone-evoked responses induced by basal forebrain stimulations in the rat auditory cortex. Exp. Brain Res. 97: $373-386$.

Elaagouby, A. and Gervais, R. 1992. ACh-induced long-lasting enhancement in excitability of the olfactory bulb. Neuroreport. 3: 10-12.

Elaagouby, A., Ravel, N., and Gervais, R. 1991. Cholinergic modulation of excitability in the rat olfactory bulb: Effect of local application of cholinergic agents on evoked field potentials. Neuroscience 45: $653-662$.

El-Etri, M.M., Ennis, M., Griff, E.R., and Shipley, M.T. 1999. Evidence for cholinergic regulation of basal norepinephrine release in the rat olfactory bulb. Neuroscience 93: 611-617.

Ennis, M., Linster, C., Aroniadou-Anderjaska, V., Ciombor, K., and Shipley, M.T. 1998. Glutamate and synaptic plasticity at mammalian primary olfactory synapses. Ann. NY Acad. Sci. 855: 457-466.

Ennis, M., Zhou, F.M., Ciombor, K.J., Aroniadou-Anderjaska, V., Hayar, A., Borrelli, E., Zimmer, L.A., Margolis, F., and Shipley, M.T. 2001. Dopamine D2 receptor-mediated presynaptic inhibition of olfactory nerve terminals. J. Neurophysiol. 86: 2986-2997.

Faber, T., Joerges, J., and Menzel, R. 1999. Associative learning modifies neural representations of odors in the insect brain. Nat. Neurosci. 2: 74-78.

Fahle, M. and Edelman, S. 1993. Long-term learning in vernier acuity: Effects of stimulus orientation, range and of feedback. Vision Res. 33: $397-412$.

Firestein, S. 2001. How the olfactory system makes sense of scents. Nature 413: 211-218.

Fleming, A.S., O'Day, D.H., and Kraemer, G.W. 1999. Neurobiology of mother-infant interactions: Experience and central nervous system plasticity across development and generations. Neurosci. Biobehav. Rev. 23: 673-685.

Fletcher, M.L. and Wilson, D.A. 2002. Experience modifies olfactory acuity: ACh-dependent learning decreases behavioral generalization between similar odorants. J. Neurosci. 22: RC201, 1-5.

. 2003. Olfactory bulb mitral/tufted cell plasticity: Odorantspecific tuning reflects prior odorant exposure. J. Neurosci. 23: 6946-6955.

Freeman, W.J. and Schneider, W. 1982. Changes in spatial patterns of rabbit olfactory EEG with conditioning to odors. Psychophysiology 19: $44-56$.

Friedrich, R.W. and Korsching, S.I. 1997. Combinatorial and chemotopic odorant coding in the zebrafish olfactory bulb visualized by optical imaging. Neuron 18: 737-752.

Gilbert, C.D., Sigman, M., and Crist, R.E. 2001. The neural basis of perceptual learning. Neuron 31: 681-697.

Givens, B. and Olton, D.S. 1994. Local modulation of basal forebrain effects on working and reference memory. J. Neurosci.

14: 3578-3587.

Godde, B., Spengler, F., and Dinse, H.R. 1996. Associative pairing of tactile stimulation induces somatosensory cortical reorganization in rats and humans. Neuroreport. 8: 281-285.

Granger, R. and Lynch, G. 1991. Higher olfactory processes: Perceptual learning and memory. Curr. Opin. Neurobiol. 1: 209-214.

Haberly, L.B. 2001. Parallel-distributed processing in olfactory cortex New insights from morphological and physiological analysis of neuronal circuitry. Chem. Senses 26: 551-576.

Halasz, N. and Shepherd, G.M. 1983. Neurochemistry of the vertebrate olfactory bulb. Neuroscience 10: 579-619.

Hasselmo, M.E. and Barkai, E. 1995. Cholinergic modulation of activity-dependent synaptic plasticity in the piriform cortex and associative memory function in a network biophysical simulation. $J$. Neurosci. 15: 6592-6604.
Hasselmo, M.E. and Bower, J.M. 1992. Cholinergic suppression specific to intrinsic not afferent fiber synapses in rat piriform (olfactory) cortex. J. Neurophys. 67: 1222-1229.

Hasselmo M.E., Anderson, B.P., and Bower, J.M. 1992. Cholinergic modulation of cortical associative memory function. J. Neurophysiol. 67: $1230-1246$

Hofer, M.A. and Sullivan, R.M. 2001. Towards a neurobiology of attachment. In Handbook of developmental cognitive neuroscience (eds C.A. Nelson and M. Luciana), pp. 599-616. MIT Press, Cambridge, MA.

Hudson, R. 1999. From molecule to mind: The role of experience in shaping olfactory function. J. Comp. Physiol. 185: 297-302.

Jehl, C., Royet, J.P., and Holley, A. 1995. Odor discrimination and recognition memory as a function of familiarization. Percept. Psychophys. 57: 1002-1011.

Jiang, M., Griff, E.R., Ennis, M., Zimmer, L.A., and Shipley, M.T. 1996. Activation of locus coeruleus enhances the responses of olfactory bulb mitral cells to weak olfactory nerve input. J. Neurosci. 16: 6319-6329.

Johnson, B.A., Ho, S.L., Xu, Z., Yihan, J.S., Yip, S., Hingco, E.E., and Leon, M. 2002. Functional mapping of the rat olfactory bulb using diverse odorants reveals modular responses to functional groups and hydrocarbon structural features. J. Comp. Neurol. 449: 180-194.

Kanter, E.D. and Haberly, L.B. 1990. NMDA-dependent induction of long-term potentiation in afferent and association fiber systems of piriform cortex in vitro. Brain Res. 525: 175-179.

Kasa, P., Hlavati, I., Dobo, E., Wolff, A., Joo, F., and Wolff, J.R. 1995. Synaptic and non-synaptic cholinergic innervation of the various types of neurons in the main olfactory bulb of adult rat: Immunocytochemistry of choline acetyltransferase. Neuroscience 67: 667-677.

Kay, L.M., Lowry, C.A., and Jacobs, H.A. 2003. Receptor contributions to configural and elemental odor mixture perception. Behav. Neurosci. 117: (in press).

Kendrick, K.M., Levy, F., and Keverne, E.B. 1992. Changes in the sensory processing of olfactory signals induced by birth in sheep. Science 256: 833-836.

Kilgard, M.P. and Merzenich, M.M. 1998. Cortical map reorganization enabled by nucleus basalis activity. Science 279: 1714-1718.

Kunze, W.A., Shafton, A.D., Kemm, R.E., and McKenzie, J.S. 1991. Effect of stimulating the nucleus of the horizontal limb of the diagonal band on single unit activity in the olfactory bulb. Neuroscience 40: $21-27$.

Leon, M. 1992. Neuroethology of olfactory preference development. J. Neurobiol. 23: $1557-1573$.

Liang, D.G. and Francis, G.W. 1989. The capacity of humans to identify odors in mixtures. Physiol. Behav. 46: 809-814.

Linster, C. and Cleland, T.A. 2002. Cholinergic modulation of sensory representations in the olfactory bulb. Neural Netw. 15: 709-717.

Linster, C. and Hasselmo, M.E. 2000. Neural activity in the horizontal limb of the diagonal band of broca can be modulated by electrical stimulation of the olfactory bulb and cortex in rats. Neurosci. Lett. 282: $157-160$.

Linster, C. and Smith, B.H. 1999. Generalization between binary odor mixtures and their components in the rat. Physiol. Behav. 66: 701-707.

Linster, C., Wyble, B.P., and Hasselmo, M.E. 1999. Electrical stimulation of the horizontal limb of the diagonal band of Broca modulates population EPSPs in piriform cortex. J. Neurophysiol. 81: 2737-2742.

Linster, C., Garcia, P.A., Hasselmo, M.E., and Baxter, M.G. 2001. Selective loss of cholinergic neurons projecting to the olfactory system increases perceptual generalization between similar, but not dissimilar, odorants. Behav. Neurosci. 115: 826-833.

Linster, C., Johnson, B.A., Morse, A., Yue, E., and Leon, M. 2002. Spontaneous versus reinforced olfactory discriminations. J. Neurosci. 22: 6842-6845.

Luskin, M.B. and Price, J.L. 1982. The distribution of axon collaterals from the olfactory bulb and the nucleus of the horizontal limb of the diagonal band to the olfactory cortex, demonstrated by double retrograde labeling techniques. J. Comp. Neurol. 209: 249-263.

Macrides, F., Davis, B.J., Youngs, W.M., Nadis, N.S., and Margolis, F.L. 1981. Cholinergic and catecholaminergic afferents to the olfactory bulb in the hamster: A neuroanatomical, biochemical and histochemical investigation. J. Comp. Neurol. 203: 497-516.

Malnic, B., Hirono, J., Sato, T., and Buck, L.B. 1999. Combinatorial receptor codes for odors. Cell 96: 713-723.

McKee, S.P. and Westheimer, G. 1978. Improvement in vernier acuity with practice. Precept. Psychophys. 24: 258-262.

McLin III, D.E., Miasnikov, A.A., and Weinberger, N.M. 2002. Induction of behavioral associative memory by stimulation of the nucleus basalis. Proc. Natl. Acad. Sci. 99: 4002-4007.

Meister, M. and Bonhoeffer, T. 2001. Tuning and topography in an odor 
map on the rat olfactory bulb. J. Neurosci. 21: 1351-1360.

Mennella, J.A. and Beauchamp, G.K. 2002. Flavor experiences during formula feeding are related to preferences during childhood. Early Hum. Devel. 68: 71-82.

Metherate, R. and Weinberger, N.M. 1989. Acetylcholine produces stimulus-specific receptive field alterations in cat auditory cortex. Brain Res. 480: 372-377.

Mori, K., Nagao, H., and Yoshihara, Y. 1999. The olfactory bulb: Coding and processing of odor molecule information. Science 286: 711-715.

Nickell, W.T. and Shipley, M.T. 1988a. Two anatomically specific classes of candidate cholinoceptive neurons in the rat olfactory bulb. $J$. Neurosci. 8: 4482-4491.

- 1988b. Neurophysiology of magnocellular forebrain inputs to the olfactory bulb in the rat: Frequency potentiation of field potentials and inhibition of output neurons. J. Neurosci. 8: 4492-4502.

Okutani, F., Yagi, F., and Kaba, H. 1999. GABAergic control of olfactory learning in young rats. Neuroscience 93: 1297-1300.

Otto, T., Cousens, G., and Herzog, C. 2000. Behavioral and neuropsychological foundations of olfactory fear conditioning. Behav. Brain Res. 110: 119-128.

Patil, M.M., Linster, C., Lubenov, E., and Hasselmo, M.E. 1998. Cholinergic agonist carbachol enables associative long-term potentiation in piriform cortex slices. J. Neurophysiol. 80: 2467-2474.

Perez-Orive, J., Mazor, O., Turner, G.C., Cassenaer, S., Wilson, R.I., and Laurent, G. 2002. Oscillations and sparsening of odor representations in the mushroom body. Science 297: 359-365.

Pettet, M.W. and Gilbert, C.D. 1992. Dynamic changes in receptive field size in cat primary visual cortex. Proc. Natl. Acad. Sci. 89: 8366-8370.

Phelps, P.E., Houser, C.R., and Vaughn, J.E. 1992. Small cholinergic neurons within fields of cholinergic axons characterize olfactory-related regions of rat telencephalon. Neuroscience 48: $121-136$

Philpot, B.D., Men, D., McCarty, R., and Brunjes, P.C. 1998. Activity-dependent regulation of dopamine content in the olfactory bulbs of naris-occluded rats. Neuroscience 85: 969-977.

Polak, E.H. 1973. Multiple profile-multiple receptor site model for vertebrate olfaction. J. Theor. Biol. 40: 469-484.

Rabin, M.D. 1988. Experience facilitates olfactory quality discrimination. Percept. Psychophys. 44: 532-540.

Rasmusson, D.D. and Dykes, R.W. 1988. Long-term enhancement of evoked potentials in cat somatosensory cortex produced by co-activation of basal forebrain and cutaneous receptors. Exp. Brain Res. 70: 276-286.

Ravel, N., Akaoka, H., Gervais, R., and Chouvet, G. 1990. The effect of acetylcholine on rat olfactory bulb unit activity. Brain Res. Bull. 24: $151-155$.

Ravel, N., Elaagouby, A., and Gervais, R. 1994. Scopolamine injection into the olfactory bulb impairs short-term olfactory memory in rats. Behav. Neurosci. 108: 317-324.

Ravel, N., Chabaud, P., Martin, C., Gaveau, V., Hugues, E., Tallon-Baudry, C., Bertrand, O., and Gervais, R. 2003. Olfactory learning modifies the expression of odour-induced oscillatory responses in the $\gamma(60-90 \mathrm{~Hz})$ and $\beta(15-40 \mathrm{~Hz})$ bands in the rat olfactory bulb. Eur. J. Neurosci. 17: 350-358.

Recanzone, G.H., Jenkins, W.M., Hradeck, G.T., and Merzenich, M.M. 1992a. Progressive improvements in discriminative abilities in adult owl monkeys performing a tactile frequency discrimination task. $J$. Neurophysiol. 67: 1015-1030.

Recanzone, G.H., Merzenich, M.M., and Schreiner, C.E. 1992b. Changes in the distributed temporal response properties of SI cortical neurons reflect improvements in performance on a temporally based tactile discrimination task. J. Neurophysiol. 67: 1071-1091.

Rochefort, C., Gheusi, G., Vincent, J.D., and Lledo, P.M. 2002. Enriched odor exposure increases the number of newborn neurons in the adult olfactory bulb and improves odor memory. J. Neurosci. 22: 2679-2689.

Rolls, E.T. 2000. Functions of the primate temporal lobe cortical visual areas in invariant visual object and face recognition. Neuron 27: 205-218.

Roman, F.S., Simonetto, I., and Soumireu-Mourat, B. 1993. Learning and memory of odor-reward association: Selective impairment following horizontal diagonal band lesions. Behav. Neurosci. 107: 72-81.

Rubin, B.D. and Katz, L.C. 1999. Optical imaging of odorant representations in the mammalian olfactory bulb. Neuron 23: $499-511$.

Saar, D., Grossman, Y., and Barkai, E. 1999. Reduced synaptic facilitation between pyramidal neurons in the piriform cortex after odor learning. J. Neurosci. 19: 8616-8622.

. 2001. Long-lasting cholinergic modulation underlies rule learning in rats. J. Neurosci. 21: 1385-1392.

Sallaz, M. and Jourdan, F. 1992. Apomorphine disrupts odour-induced patterns of glomerular activation in the olfactory bulb. Neuroreport. 3: $833-836$.

Sarter, M. and Bruno, J.P. 1997. Cognitive functions of cortical acetylcholine: Toward a unifying hypothesis. Brain Res. Rev. 23: $28-46$.

Shute, C.C.D. and Lewis, P.R. 1967. The ascending cholinergic reticular system: Neocortical, olfactory, and subcortical projections. Brain 90: $497-520$.

Stripling, J.S., Patneau, D.K., and Gramlich, C.A. 1988. Selective long-term potentiation in the pyriform cortex. Brain Res. 441: 281-291.

Sullivan, R.M. and Wilson, D.A. 1994. The locus coeruleus, norepinephrine, and memory in newborns. Brain Res. Bull. 35: 467-472.

Sullivan, R.M., Wilson, D.A., and Leon, M. 1989. Norepinephrine and learning-induced plasticity in infant rat olfactory system. J. Neurosci. 9: $3998-4006$.

Sullivan, R.M., Zyzak, D.R., Skierkowski, P., and Wilson, D.A. 1992. The role of olfactory bulb norepinephrine in early olfactory learning. Devel. Brain Res. 70: 279-282.

Sullivan, R.M., Wilson, D.A., Lemon, C., and Gerhardt, G.A. 1994. Bilateral 6-OHDA lesions of the locus coeruleus impair associative olfactory learning in newborn rats. Brain Res. 643: 306-309.

Sullivan, R.M., Landers, M., Yeaman, B., and Wilson, D.A. 2000a. Good memories of bad events in infancy. Nature 407: 38-39.

Sullivan, R.M., Stackenwalt, G., Nasr, F., Lemon, C., and Wilson, D.A. $2000 \mathrm{~b}$. Association of an odor with activation of olfactory bulb noradrenergic $\beta$-receptors or locus coeruleus stimulation is sufficient to produce learned approach responses to that odor in neonatal rats. Behav. Neurosci. 114: 957-962.

Tsuboi, A. 1999. Olfactory neurons expressing closely linked and homologous odorant receptor genes tend to project their axons to neighboring glomeruli on the olfactory bulb. J. Neurosci. 19: 8409-8414.

Uchida, N., Takahashi, Y.K., Tanifuji, M., and Mori, K. 2000. Odor maps in the mammalian olfactory bulb: Domain organization and odorant structural features. Nat. Neurosci. 3: 1035-1043.

Vassar, R., Chao, S.K., Sitcheran, R., Nunez, J.M., Vosshall, L.B., and Axel, R. 1994. Topographic organization of sensory projections to the olfactory bulb. Cell 79: 981-991.

Wachowiak, M. and Cohen, L.B. 1999. Presynaptic inhibition of primary olfactory afferents mediated by different mechanisms in lobster and turtle. J. Neurosci. 19: 8808-8817.

. 2001. Representation of odorants by receptor neuron input to the mouse olfactory bulb. Neuron 32: 723-735.

Weinberger, N.M. 1995. Dynamic regulation of receptive fields and maps in the adult sensory cortex. Annu. Rev. Neurosci. 18: 129-158.

Wenk, H., Meyer, U., and Bigl, V. 1977. Centrifugal cholinergic connections in the olfactory system of rats. Neuroscience 2: 797-800.

Wilson, D.A. 1998a. Habituation of odor responses in the rat anterior piriform cortex. J. Neurophysiol. 79: 1425-1440.

1998b. Synaptic correlates of odor habituation in the rat anterior piriform cortex. J. Neurophysiol. 80: 998-1001.

2001. Scopolamine enhances generalization between odor representations in rat olfactory cortex. Learn. Mem. 8: 279-285.

2003. Rapid, experienced-induced enhancement in odorant discrimination by anterior piriform cortex neurons. J. Neurophysiol. 90: $65-72$

Wilson, D.A. and Stevenson, R.J. 2003. The fundamental role of memory in olfactory reception. TINS 26: 243-247.

Wilson, D.A. and Sullivan, R.M. 1994. Neurobiology of associative learning in the neonate: Early olfactory learning. Behav. Neural Biol. 61: $1-18$.

. 1995. The D2 antagonist spiperone mimics the effects of olfactory deprivation on mitral/tufted cell odor response patterns. $J$. Neurosci. 15: 5574-5581.

Wilson, D.A., Sullivan, R.M., and Leon, M. 1987. Single-unit analysis of postnatal olfactory learning: Modified olfactory bulb output response patterns to learned attractive odors. J. Neurosci. 7: 3154-3162.

Woo, C.C., Oshita, M.H., and Leon, M. 1996. A learned odor decreases the number of Fos-immunopositive granule cells in the olfactory bulb of young rats. Brain Res. 716: 149-156.

Xing, J. and Gerstein, G.L. 1994. Simulation of dynamic receptive fields in primary visual cortex. Vision Res. 34: 1901-1911.

Zaborszky, L., Carlsen, J., Brashear, H.R., and Heimer, L. 1986. Cholinergic and GABAergic afferents to the olfactory bulb in the rat with special emphasis on the projection neurons of the horizontal limb of the diagonal band. J. Comp. Neurol. 243: 488-509.

Zou, Z., Horowitz, L.F., Montmayeur, J.P., Snapper, S., and Buck L.B. 2001. Genetic tracing reveals a stereotyped sensory map in the olfactory cortex. Nature 414: $173-179$.

\section{Learning \& Memory}




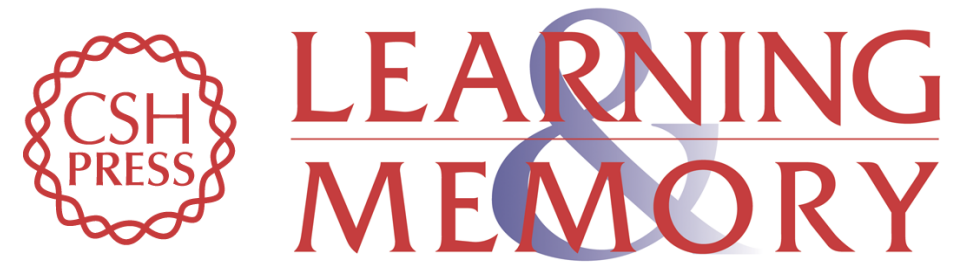

\section{Acetylcholine and Olfactory Perceptual Learning}

Donald A. Wilson, Max L. Fletcher and Regina M. Sullivan

Learn. Mem. 2004, 11:

Access the most recent version at doi:10.1101/lm.66404

References This article cites 124 articles, 29 of which can be accessed free at: http://learnmem.cshlp.org/content/11/1/28.full.html\#ref-list-1

License

Email Alerting Receive free email alerts when new articles cite this article - sign up in the box at the Service top right corner of the article or click here. 